\title{
O DIRETOR DE COMUNICAÇÃO NO FUTEBOL: PERFIS E TENDÊNCIAS NOS "TRÊS GRANDES" CLUBES PORTUGUESES
}

\author{
José de Lemos Quintela \\ ISCTE - Instituto Universitário de Lisboa; CIES-IUL (Portugal) \\ ISG - Instituto Superior de Gestão (Portugal) \\ jeccl@iscte-iul.pt
}

\section{Resumo}

Objetivo do estudo: Traçar o perfil do Diretor de Comunicação (DirCom) nos grandes clubes do futebol português e analisar a sua atividade, não só enquanto pivô do processo comunicativo, mas também como protagonista de um processo de comunicação, influência e poder. Pretende-se assim analisar as competências necessárias para o exercício desta função.

Metodologia/abordagem: A partir de uma revisão da literatura problematizamos a centralidade midiática do DirCom, tendo como estratégia metodológica a observação participante completa no Sporting Clube de Portugal. Foi ainda efetuada uma análise documental, de caráter descritivo/comparativo, da imprensa desportiva, currículos e trajetos profissionais dos DirCom dos "três grandes" (Benfica, Porto e Sporting).

Originalidade/relevância: A centralidade da função DirCom nas Sociedades Anônimas Desportivas (SAD) em Portugal não encontra, ainda, correspondência ao nível das pesquisas acadêmicas e científicas desenvolvidas. Este estudo exploratório ganha relevância ao contribuir para o aprofundamento e conhecimento deste assunto.

Principais resultados: $\mathrm{O}$ perfil identificado caracteriza-se pela senioridade, experiência política e empresarial dos DirCom, em detrimento da esportiva. São privilegiados modelos de comunicação unidirecionais (propagandísticos) num ecossistema comunicacional que proporciona aos clubes um maior controle sobre as suas mensagens, com as suas próprias plataformas de comunicação e sem necessidade de intermediação jornalística.

Contribuições teóricas/metodológicas: Promove a discussão da relação entre a mercantilização, a política e o futebol, em torno do DirCom e o seu papel na atualidade, objeto por explorar.

Contribuições sociais/para a gestão: Analisa o papel do DirCom na governança das SAD e na relação com os stakeholders, num mundo cada vez mais digital, abrindo caminho a novas pesquisas.

Palavras-chave: Comunicação. DirCom. Futebol. Poder. Relações Públicas.

\section{Cite como}

American Psychological Association (APA)

Quintela, J. de L. (2020). O diretor de comunicação no futebol: perfis e tendências nos "três grandes" clubes portugueses. PODIUM Sport, Leisure and Tourism Review, São Paulo, 9(1), 21-41. https://doi.org/10.5585/podium.v9i1.13748.

Projecto Financiado pela FCT - Fundação para a Ciência e Tecnologia, Bolsa de Investigação, com a referência SFRH/BD/144278/2019. 


\title{
EL DIRECTOR DE COMUNICACIÓN EN EL FÚTBOL: PERFILES Y TENDENCIAS EN LOS PRINCIPALES CLUBES PORTUGUESES
}

\section{RESUMEN}

Objetivo del estudio: Delinear el perfil del Communication Director (DirCom) en los principales clubes de fútbol portugueses y analizar su actividad, no solo como eje del proceso comunicativo, sino también como protagonista de un proceso de comunicación, influencia y poder. De esta manera, se pretenden analizar las competencias necesarias para el ejercicio de esta función.

Metodología: En base a una revisión de la literatura más significativa, cuestionamos la centralidad mediática del DirCom, utilizando como estrategia metodológica la observación participante completa en el Sporting Clube de Portugal. También se llevaron a cabo análisis documentales, descriptivos/comparativos, de la prensa deportiva, de los currículos y de las trayectorias profesionales de los DirCom de los tres principales equipos de fútbol portugueses (Benfica, Porto y Sporting).

Relevancia: La centralidad de la función del DirCom en las Sociedades Anónimas Deportivas Portuguesas (SAD) en Portugal aún no encuentra correspondencia a nivel de estudios académicos y científicos desarrollados. Este trabajo exploratorio es relevante porque contribuye a la profundización y al conocimiento de este tema.

Resultados principales: El perfil identificado se caracteriza por la "seniority" de los DirCom, por su experiencia política y empresarial, en detrimento de la deportiva. Se favorecen los modelos de comunicación unidireccional (más propagandística) en un ecosistema comunicacional que da a los clubes un mayor control sobre sus mensajes, al tener sus propias plataformas de comunicación sin la necesidad de intermediación periodística.

Contribuciones teóricas: Este estudio promueve la discusión de la relación entre el mercantilismo, la política y el fútbol en torno al DirCom y su papel actual, un objeto a explorar.

Contribuciones de gestión: El papel del DirCom en la gobernanza de las SAD y en la relación con las partes interesadas, en un mundo cada vez más digitalizado, abriendo el camino para nuevas investigaciones.

Palabras claves: Comunicación. DirCom. Fútbol. Poder. Relaciones Públicas.

\section{THE COMMUNICATION DIRECTOR IN FOOTBALL: PROFILES AND TRENDS IN MAJOR PORTUGUESE CLUBS}

\begin{abstract}
Objective: The objective is to outline the profile of the Communication Director (DirCom) in the major Portuguese football clubs and to analyze his activity, not only as pivot of the communicative process, but also as a protagonist of a process of communication, influence and power. In this way, the article intends to analyze the necessary skills for this job.
\end{abstract}


Methodology/approach: Upon a review of the most significant literature, the study questioned the centrality of the DirCom of Portuguese football in the media, having as methodological strategy the complete participant observation in Sporting Clube de Portugal. The documental analysis, descriptive and comparative, focused on the sports press, curricula and professional trajectories of the DirCom of the three major Portuguese football clubs (Benfica, Porto and Sporting).

Originality/relevance: The centrality of the DirCom function in Sports Societies (SADs) in Portugal still does not find correspondence with academic and scientific studies developed. This exploratory study gains relevance by contributing to a deeper knowledge of the subject.

Main results: The profile identified is characterized by the DirCom's seniority, political and business experience, to the detriment of a sports background. Unidirectional (more propagandistic) communication models are privileged in a communicational ecosystem that gives clubs greater control over their messages, with their own communication platforms and without the need for journalistic intermediation.

Theoretical/methodological contributions: The article promotes the discussion of the interconnection between business, politics and football around the figure of the DirCom and its current role, an object to be explored.

Social/management contributions: The role of DirCom in the governance of SADs and in the relationship with stakeholders, in an increasingly digitalized world, opening the way for new investigations.

Keywords: Communication. DirCom. Football. Power. Public relations.

\section{Introdução}

O futebol sempre foi mais do que o jogo realizado entre as quatro linhas (Giulianotti \& Robertson, 2012; Penn, 2016). O jogo, propriamente dito, passou a ser apenas a sua expressão máxima (Lopes, Loureiro \& Vieira, 2011), aquela que é visível, que lhe dá sentido e o justifica, pelo que, "ao tornar-se o esporte mais praticado e também o mais difundido através das mídias, transformou-se num veículo de expressão de identidade na nossa sociedade, quer para quem o pratica, quer para quem a ele assiste" (Cardoso, Xavier \& Cardoso, 2007, p. 120). No entanto, há um conjunto de outras dimensões a envolverem-no, sejam estas políticas, econômicas ou sociais (Marivoet, 2009; Daniel, 2016), que lhe dão corpo e projeção (Wagg, 2007; Ginesta, 2009).

A comunicação é central na atividade dos grandes clubes de futebol, está presente no cotidiano de milhões de pessoas e é transversal nas sociedades contemporâneas. É neste contexto que exploramos o papel do Diretor de Comunicação (DirCom) nos grandes clubes do futebol português, naquela que é uma modalidade cada vez mais midiática (Coelho \& Tesler, 2006). Em Portugal, no período entre 1 de janeiro e 30 de novembro de 2018 (Cision, 2018), foram publicadas 589.407 notícias sobre futebol. As rádios e TVs lhe dedicaram 14.550 horas de emissão, sem incluir as transmissões de jogos. Estamos perante um número de horas que equivale a mais de 606 dias, enquanto o ano só teve 365. Existem ainda inúmeras páginas de 
torcedores dedicadas ao futebol em redes sociais, sites e blogs (Kumar, 2009; Gouveia \& Cardoso, 2019).

Neste "circo midiático", surge enquanto ator do fenômeno futebolístico o DirCom, mas com uma intervenção diferente daquela que vinha desenvolvendo até aqui: se anteriormente se movia sobretudo nos bastidores e com uma intervenção pautada pela discrição e anonimato, agora o seu papel vai além de pivot comunicacional, assumindo-se como protagonista naquilo que pode ser considerado um complexo sistema de relações e interesses conflitantes, como é o "mundo do futebol" (Pinheiro, 2011). No entanto, apesar de toda esta centralidade e midiatismo e do que os DirCom podem possibilitar enquanto objeto de estudo, se verifica que em termos acadêmicos e científicos o seu conhecimento é praticamente nulo. Falamos concretamente do papel do DirCom, bem como dos profissionais que exercem estas funções em Sociedades Anônimas Desportivas (SAD), apesar de se encontrarem já alguns estudos sobre os departamentos de comunicação dos clubes (Olabe, 2009). As pesquisas desenvolvidas não têm acompanhado a dimensão que este fenômeno vem evidenciando, uma lacuna que carece de ser colmatada, para o que pretendemos contribuir.

A Liga NOS é a principal competição do futebol profissional em Portugal, sendo constituída por 18 clubes. O Futebol Clube do Porto, Sport Lisboa e Benfica e Sporting Clube de Portugal, por ordem alfabética e não por ordem de grandeza, são os três maiores clubes. E até "muitas crianças aprenderam a distinguir o azul, o vermelho e o verde a partir da correspondência com as cores dos «três grandes»" (Coelho \& Tesler, 2006, p. 523), que representam, em termos de massa adepta, $85 \%$ da preferência dos torcedores portugueses (Sá \& Reto, 2002, p. 236). Ou seja, há duas realidades: os "três grandes" e os "outros".

A presente pesquisa é de caráter exploratório e versa sobre a centralidade midiática dos DirCom dos "três grandes" clubes de futebol em Portugal. A estratégia metodológica seguida contemplou a observação participante completa (Adler \& Adler, 1987), no Sporting Clube de Portugal, a par da análise documental de artigos de imprensa dos três jornais diários esportivos portugueses ( $A$ Bola, Record e $O$ Jogo) e de uma análise descritiva e comparativa dos currículos e trajetos profissionais desses DirCom. O estudo incide sobre a época esportiva 2017/18, caracterizada pelo elevado protagonismo midiático dos DirCom e de uma prática comunicacional com forte crispação entre os clubes, num clima de guerrilha permanente.

Tentamos compreender as razões da aparente aparição de "geração espontânea" do DirCom no futebol português, que invade o espaço midiático. Quais as razões que a motivaram ou motivam? Terão existido mudanças na atividade das Sociedades Anônimas Desportivas que nos ajudem a compreender estas alterações? Se sim, quais foram? E ao nível dos profissionais, que alterações existiram? Quem é que assume estas funções, quem são e de onde vêm?

Pretendemos assim explorar os aspectos que possam ter contribuído para esse "estrelato", bem como eventuais consequências que possam eventualmente produzir na relação com os diferentes públicos/stakeholders, em especial com as mídias. Importa assim perceber as alterações verificadas e o que elas significam ou podem significar. Tanto mais que o DirCom é uma figura central do fenômeno comunicacional do futebol, um ator de quem nada ou pouco se conhece e ao qual as pesquisas acadêmicas e científicas pouco ou nenhuma atenção têm dedicado.

Discutimos o protagonismo assumido pelos DirCom, no âmbito do relacionamento entre público e organização (clubes), quando se assiste a uma alteração do sistema comunicacional dos clubes de futebol. Isto, num ambiente fortemente concorrencial, com uma mercantilização crescente, onde a digitalização das mídias veio contribuir ainda mais para uma alteração significativa do seu ecossistema comunicacional (Moragas, 2012). Para compreendermos estas transformações, analisamos os perfis destes profissionais (DirCom) à luz das alterações verificadas no fenômeno futebolístico e em diferentes dimensões. Falamos concretamente do 
maior controle por parte dos clubes sobre as suas mensagens, através da adoção de modelos integrados de gestão da comunicação e posse das suas próprias plataformas de comunicação. Nestas últimas, evidenciamos o fato de não necessitarem de qualquer intermediação jornalística, o que altera toda a lógica comunicacional até aqui seguida.

Os clubes passam a privilegiar modelos de comunicação unidirecionais, o que, de acordo com os quatro modelos de relações públicas apresentados por Grunig \& Hunt (1984), correspondem aos dois primeiros, designados "Agente de Imprensa/Publicity" e "Informação Pública". Estes caracterizam-se essencialmente pela desinformação/propaganda e pela disseminação da informação.

A evolução do fenômeno futebol implicou que as organizações e estruturas esportivas tivessem de acompanhar os novos desafios (Moragas, 2012). Assim, assistimos a sistemas mais sofisticados e complexos, com novas dinâmicas e multiplicidade de interações (Grunig \& Hunt, 1984). Neste processo, a comunicação e o futebol, enquanto parte do todo organizacional, foram conhecendo mutações (Olabe, 2009) e uma maior centralidade na sociedade (Tiesler \& Coelho, 2006; Moragas, 2012). Como afirma Sobral (2017, p. 84), "futebol é muito mais que um esporte. É política. E é poder". Passamos assim de uma realidade singular de jogo para a pluralidade de "jogos", ou seja, ventila-se a ideia de vários "gramados" de competição, campos de jogos de influência, de comunicação e de poder: "há mais «futebóis» no mundo do futebol" (Gastaldo \& Helal, 2013, p. 121). Tudo isto é marcado pela onipresença das mídias na atividade dos clubes, num mundo midiatizado (Tench, Verčič, Zerfass, Moreno \& Verhoeven, 2017) onde a percepção ganha força de realidade, tanto para quem assiste aos fenômenos como para aqueles que neles intervêm (Quintela, 2006).

É este conjunto de alterações que pode eventualmente explicar o perfil identificado neste estudo, em que surge uma tendência para privilegiar um perfil de DirCom com maior correspondência ao homem político e empresário, em detrimento do típico perfil do exjornalista esportivo que até aqui caracterizava a comunicação dos grandes clubes profissionais do futebol português.

\section{Referencial teórico}

\section{Os clubes e a onipresença das mídias}

O poder é visto como um jogo de representações, tal como o teatro (Balandier, 1999), mas também na forma como é exercido (Habermas, 1991), o que "faz do poder quase vítima, senão mesmo sujeito submetido à tirania da sua representação midiática" (Cunha, 1999, p. 11). Este, sendo um jogo de representações, é também inevitavelmente um campo de percepções e consequentemente de imagem. Esta, por sua vez, é precedida pela identidade, a qual constitui a prioridade das estratégias de comunicação (Kapferer, 2000). A identidade é um conceito de emissão, enquanto que a imagem está associada a um conceito de recepção; para esta se verificar, há que necessariamente emitir primeiro (Kapferer, 2000; Quintela, 2015). Torna-se assim relevante perceber quem os stakeholders compreendem como detentores do poder, independentemente de este ser real. Trata-se de uma situação similar ao processo de decisão de um investidor, ao decidir em função daquilo que intuiu vir a ser a evolução de determinado investimento (Quintela, 2006). É possível o entendimento que quem detém o poder, seja individual ou coletivo, numa estrutura formal ou informal, pode condicionar ou condiciona mesmo o processo de decisão, pois esses atores, ao serem entendidos como titulares de poder, independentemente de este ser real ou não, implicam ou podem implicar aqueles que nesses meios se movimentam ou observam (Quintela et al., 2007; Cardoso et al., 2007). 
Vivemos na onipresença da mídia, num mundo midiatizado, considerando Tench et al. (2017, p. 29) que na gestão da comunicação midiatizada existem três faces: a primeira, segundo os autores, corresponde a uma visão clássica, com as tradicionais relações com a imprensa e a mídia jornalística; uma segunda assenta-se na comunicação mediada por computador ou mídia social; e a terceira é relativa ao futuro, a "midiatização estratégica onde as oportunidades são tomadas e as alianças com empresas de mídia estão a ser desenvolvidas para alcançar novos públicos, como marketing de conteúdo, publicidade nativa e jornalismo de marca" (Tench et al., 2017, p. 29). Neste contexto, percebe-se que as plataformas de comunicação assumam um papel preponderante ao conhecerem novas formas de expressão (Daymon \& Holloway, 2011) e ao fazerem uso do avanço tecnológico, que nos permite conectar à escala global (Castells, 2004). Estas aumentam o imediatismo, o midiatismo (Balandier, 1999), a interação, mas também o escrutínio. "Tenho más notícias para si: mesmo que não se relacione com as redes, as redes vão relacionar-se consigo... porque vivemos na Galáxia Internet" (Castells, 2004, p. 325), numa sociedade em rede. Mas quando a "Aldeia Global" foi idealizada por Marshall McLuhan $(1962 ; 1964)$ ainda não existia Internet e isso faz toda a diferença, pois atualmente as organizações comunicam com os seus públicos não só pelos mass media, mas através dos social media (Tench et al., 2017).

A digitalização da comunicação trouxe novas oportunidades e teve implicações diretas e multidimensionais nas organizações esportivas (Ginesta, 2009; Moragas, 2012). Os torcedores vivem a sua paixão para lá dos estádios, "de forma indireta, através da mídia televisiva ou de outra, através de outras formas de sociabilidade à volta do tema" (Coelho \& Tesler, 2006, p. 524), sendo as redes sociais paradigmáticas neste particular. Mas nesta onipresença das mídias temos que considerar ainda as alterações registradas ao nível dos conteúdos disponibilizados e o respectivo processo produtivo (L'Étang, 2006). Neste último incluímos as fontes de informação vitais nos meios jornalísticos, nomeadamente as fontes profissionais (Santos R., 1997), que assumem um papel central que importa explorar, tanto mais que têm registrado alterações significativas ao nível das organizações que interagem no fenômeno futebolístico, "estando o papel das relações públicas sub-explorado, bem como o seu contributo para o desenvolvimento do negócio do esporte" (L’Étang, 2006, p. 389). Os clubes, ao deterem suas próprias plataformas de comunicação, passaram a ter maior controle sobre suas mensagens, ganharam autonomia dos meios tradicionais e libertaram-se da obrigatoriedade da intermediação jornalística. Com isto gerem o que dizer, a quem dizer, como dizer e quando dizer, sem qualquer tipo de contraditório.

\section{A relação público-organização}

Tomando por base a teoria relacional (Cutlip, Center \& Broom, 1999; Ledingham, 2003; Huang \& Zhang, 2015), importa explorar o papel da comunicação e de seus protagonistas na afirmação de seus interesses, concretamente através dos DirCom, que, ao depender diretamente da administração e numa função de staff, podem aconselhar a tomada de decisão daquela (Cornelissen, 2011). Eles comunicam e explicam as posições do poder para que estas decisões, mais do que ser entendidas, sejam aceitas (Ramalho, 1982). O poder desenvolve-se em torno de "valores" e "instituições", sendo aquilo que "valora" e "institucionaliza" definido pelas próprias relações de poder (Castells, 2009, p. 33). Os mecanismos de poder desenvolvem-se através de mensagens comunicativas (informação) que atuam sobre a mente humana, daí a relevância de entender como essas mensagens se traduzem em ações (Castells, 2009, p. 33). Mas, "se o poder é a capacidade ou o potencial de fazer as coisas, então a influência é o uso, a expressão ou a realização do poder" (Berger \& Reber, 2006, p. 4). A influência é assim uma 
tentativa intencional, explícita ou não, de agir sobre o pensamento, atitudes ou comportamento de alguém e que, sendo sobretudo estratégica, é, no entanto, também política (Shi \& Wilson, 2017).

Para Mintzeberg et al. (1998, p. 174), a Escola de Poder "abre o jogo e caracteriza a formação da estratégia como um processo aberto de influência, enfatizando o uso de poder e da política para negociar estratégias favoráveis a determinados interesses", sendo que "poder" é utilizado no sentido de descrever "o exercício de influência", mas mais próximo do sentido político do que do estritamente econômico. Os mesmos autores consideram que as "as relações de poder cercam as organizações; mas também podem inspirá-las", distinguindo dois tipos de poder: o micro e o macro. O primeiro respeita a "indivíduos e grupos dentro da organização" (1998, p. 183), enquanto o segundo "reflete a interdependência de uma organização com o seu ambiente", em linha com uma visão sistêmica e com o relacionamento entre a organização e os seus públicos/stakeholders (Grunig \& Hunt, 1984; Grunig \& Repper, 1992).

O relacionamento entre as organizações e o público (Cheng, 2018) na ótica das relações públicas deve estar por estas gerido no sentido de contribuir para a eficácia das organizações. Grunig (1992) desenvolveu a primeira teoria de excelência em relações públicas, mas só após ter identificado, em conjunto com Hunt (Grunig \& Hunt, 1984, pp. 21-46), os quatro modelos das relações públicas, na teoria e na prática: "Assessoria de Imprensa/Publicity", "Informação Pública", "Assimétrico Bidirecional" e "Simétrico Bidirecional". Convém salientar que estes modelos vêm introduzir uma dimensão ética na teoria das relações públicas e contrariar a ideia de disciplina associada à manipulação e propaganda preconizada praticamente desde suas origens.

Edward Bernays $(1923 ; 1928)$, uma das principais referências das origens das relações públicas, considerava que manipular ou promover princípios, valores, ideais, personalidades ou acontecimentos era fundamental, constituindo mesmo um importante elemento das sociedades democráticas. Nos quatro modelos de Grunig \& Hunt (1984), os três primeiros são modelos assimétricos e apenas o quarto é simétrico. Os primeiros correspondem a práticas que visam apenas persuadir o público em proveito próprio, ou seja, próximas das práticas propagandísticas. Apenas o quarto modelo entende os profissionais das relações públicas enquanto mediadores das organizações e seus públicos, visando o entendimento mútuo e utilizando as teorias da comunicação para planejarem e avaliarem as suas atividades, em detrimento das teorias da persuasão. Centram-se na negociação e no compromisso, numa relação mais equilibrada, tanto ao nível de poder como de iniciativa, favorecendo uma gestão de conflitos mais eficaz.

Tal como as pessoas, as organizações não vivem isoladas no mundo, havendo que gerir um conjunto vasto de relações e relacionamentos. Estes grupos de indivíduos ou de instituições que se relacionam com uma organização são designados nas relações públicas (RP) por "públicos" (Grunig \& Hunt, 1984; Grunig \& Jeong-Nam Kim, 2017) ou stakeholders (Freeman, 1984). Embora existam diferenças conceptuais entre elas, não o faremos neste contexto, quando as utilizarmos. As organizações são tão mais eficazes quanto melhor consigam definir e atingir os seus objetivos, em função dos seus próprios interesses, mas também em função dos seus públicos estratégicos, os quais integram o seu meio ambiente (Grunig, 1996). Os públicos devem ser entendidos como um tipo de segmentação utilizado nas relações públicas, podendo "ser segmentados de acordo com a vivência de problemas; e o que faz a diferença da resposta é a natureza do seu comportamento de comunicação relacionado com esses problemas". (Grunig \& Jeong-Nam Kim, 2017). Moragas (2012, pp. 23-24) considera que o esporte e a comunicação no novo contexto global assiste a uma profunda transformação em que sistemas complexos de comunicação têm uma estrutura que pode ser analisada em quatro grupos 
principais de atores: "os concorrentes esportivos"; "a comunicação"; os "negócios" e a "comunidade". É precisamente sobre a comunicação que nos centramos.

\section{Procedimentos metodológicos}

Tendo por objetivo traçar o perfil dos DirCom dos três maiores clubes portugueses Futebol Clube do Porto (Porto), Sport Lisboa e Benfica (Benfica), Sporting Clube de Portugal (Sporting) -, opção que se justifica por estes clubes representarem $85 \%$ da preferência dos torcedores portugueses (Sá \& Reto, 2002, p. 236), e definir os respectivos posicionamentos comunicacionais na Liga NOS, na época desportiva 2017/18, fez-se uso de um conjunto de métodos qualitativos. Em termos metodológicos, socorremo-nos da análise documental, "um método útil por causa da sua natureza não-intrusiva e não-reativa" (Daymon \& Holloway, 2011, p. 278), de forma a nos permitir um acesso a informação e a pessoas que de outra forma poderia ser difícil ou impossível.

A análise documental foi efetuada através de leituras flutuantes (Bardin, 1977), tendo sido realizada com base nos três principais jornais diários de esporte portugueses - $A$ Bola, $O$ Jogo e Record - no período correspondente à época em análise. Como tal, incidiu sobretudo em notícias da imprensa esportiva, tentando identificar atores, temáticas, sentimentos relativos aos assuntos e posicionamentos comunicacionais. Após selecionarmos os documentos, foram identificados atores e temáticas abordados ao longo da época 2017/18 e respectivos posicionamentos, os quais utilizamos na análise dos resultados. Fizemos ainda uso da observação participante completa (Adler \& Adler, 1987), no Sporting Clube de Portugal, em que o investigador esteve envolvido no grupo como "nativo", observando o trabalho desenvolvido pelo DirCom, no período entre 1 de julho de 2017 e 13 de maio de 2018.

As relações foram desenvolvidas num mesmo plano, "compartilhando em conjunto experiências, sentimentos e objetivos comuns" (Adler \& Adler, 1987, p. 67). Uma das principais vantagens deste tipo de observação participante completa é a liberdade de movimentos e livre acesso aos dados (Adler \& Adler, 1987, p. 67), o que se verificou no caso em estudo. No entanto, como apontam os mesmos autores, o risco de demasiado envolvimento e de este poder enviesar a análise é uma possibilidade, pela eventual perda de objetividade (Abib, Hoppen, \& Junior, 2013).

Os dados coletados ao longo do período em análise resultaram tanto das observações das reuniões formais como de encontros informais, como são as "conversas de corredor", tendo estas sido registradas no caderno de campo. Houve a preocupação de registrar nas notas de campo todas as situações em que o DirCom manifestava uma posição sobre a sua atividade ou sobre a dos seus adversários. Tal ocorreu sem que isso interferisse no trabalho cotidiano do DirCom, razão pela qual se optou por este tipo de registro e não pela gravação de voz. Se procurou ainda compreender as razões de determinadas tomadas de decisão e sentimentos relativos aos assuntos e atores envolvidos.

Foi observado o trabalho do DirCom no âmbito da governança corporativa, a sua práxis e as estratégias desenvolvidas. Este método permitiu que, ao longo da observação, os fatos observados pudessem ser discutidos com o informante (DirCom), ficando reservada a respectiva interpretação aos pesquisadores (Angrosino, 2009).

Quanto ao risco de perda da objetividade, estivemos conscientes desta situação e procuramos sempre fazer uma análise fatual, nos centrando nos aspectos técnicos e registrando as tomadas de posição do DirCom do Sporting, bem como as que publicamente eram divulgadas pelos DirCom do Benfica e do Porto, tanto nas mídias tradicionais como através das redes 
sociais. Tentamos sempre suportar a análise em dados objetivos e em fontes dos diversos quadrantes clubísticos alvo do estudo.

Feitas estas considerações, prosseguimos para traçar o perfil dos DirCom, definindo um conjunto de variáveis e uma tabela de análise tendo como referência o European Communication Report/European Monitor (European Association of Communication Directors, 2008); Zerfass et al., 2009, 2018) A tabela de análise foi elaborada considerando as variáveis seguintes: demográficas; educacionais; carreira profissional; integração nas estruturas organizacionais; utilização de plataformas de comunicação e preferências políticas.

\section{Análise de resultados}

A época esportiva 2017/18, além da rivalidade histórica entre os "três grandes" (Coelho \& Tesler, 2006), foi caracterizada por uma conflitualidade elevada com a comunicação dos clubes no centro das atenções, como podemos verificar em inúmeros relatos publicados na imprensa (Crespo, 2018; Santos R. M., 2019) e que motivaram inclusive que o governo português tomasse posição face à tensão crescente (Forte, 2017). Assistimos a casos de denúncia de corrupção, tráfico de influências, viciação de resultados e violência. Uma das situações mais paradigmáticas é o "caso e-mails", relacionado com as caixas de correio eletrônico do Benfica, que terão sido alegadamente invadidas por um haker, sendo o seu conteúdo divulgado publicamente, entre outros, pelo DirCom portista no Porto Canal ${ }^{1}$ (Record, 2018). A denúncia criou um manto de suspeitas, motivou debates e uma guerra nas mídias entre os DirCom, com acusações mútuas, investigações e processos judiciais, alguns dos quais estão ainda em curso (Record, 2018).

Além de pivôs da comunicação, os DirCom foram também protagonistas da "guerra midiática", usando intensamente as plataformas de comunicação dos clubes (canais de TV, jornais, sites e redes sociais). Criaram nos seus canais programas onde eram comentadores residentes ou presenças regulares, numa lógica de comunicação de guerrilha. De acordo com Lopes (2011, p. 76), "se a entrada nos plateaux televisivos privilegia aqueles que já conquistaram alguma importância dentro do seu grupo, a visibilidade midiática que a televisão proporciona revela-se um meio estruturante da identidade pública desses atores".

O DirCom do Porto teve a sua tribuna no programa Universo Porto, onde semanalmente se dedicou ao "caso $e$-mails". Em resposta, a $\mathrm{BTV}^{2}$ lançou o programa Chama Imensa (Sport Lisboa e Benfica, 2017), iniciando as emissões com suspeitas sobre o Porto, naquilo que designou como novo "Apito Dourado". 3 Seguiu-se o DirCom do Sporting na Sporting TV, com o Verde no Branco, programa semanal que, na sua estreia, denunciou o Benfica por apoio ilegal à torcida organizada (Fernandes, 2017). Para Rui Santos, são os clubes que estimulam a mídia a falar mais de aspectos colaterais, "algumas espertezas saloias fomentadas pelos departamentos de comunicação, que pegam em tudo e mais alguma coisa para intoxicar e desviar as atenções..." (Santos R. M., 2019, p. 24). As práticas desenvolvidas, como se verifica, estão em linha com os dois primeiros modelos de Grunig \& Hunt (1984), "Assessoria de Imprensa/Publicity" e "Informação Pública".

\footnotetext{
${ }^{1}$ Porto Canal: canal de televisão oficial do Futebol Clube do Porto.

${ }^{2}$ BTV: canal de televisão oficial do Sport Lisboa e Benfica.

${ }^{3}$ Escândalo de corrupção no futebol português despoletado em 2004 e cujas escutas telefónicas foram tornadas públicas e envolviam o Futebol Clube do Porto.

${ }^{4}$ Sporting TV: canal de televisão oficial do Sporting Clube de Portugal.
} 
Os meios utilizados naquilo que podemos designar como a "guerrilha dos DirCom" assumiram também a forma de livro, através do DirCom do FC Porto. Em Novembro de 2017, este foi coautor de $O$ Polvo Encarnado: Os Esquemas, Manipulações e Compadrios que Viciam o Futebol Português" (Marques \& Faria, 2017, p. 2), livro com o objetivo de "apresentar, em todo o seu esplendor, o polvo encarnado...". 5

Os DirCom passaram a estrelas do circo midiático, tal como evidencia Tiago Palma (Palma, 2017) num trabalho jornalístico sobre os DirCom do Porto e do Sporting, ao considerar "que se tornaram mediáticos nos últimos tempos por causa das posições que defendem (e, sobretudo, no tom em que as defendem e nas polémicas que criam) nos respetivos clubes - o que lhes granjeou mediatismo, sim, mas também o fim da vida privada como outrora a tiveram”.

Na tabela 1 são apresentados os dados disponibilizados pela Cision relativos ao número de notícias publicadas sobre os presidentes da Federação Portuguesa de Futebol (FPF) e da Liga Portuguesa de Futebol Profissional (Liga), e sobre os DirCom dos três grandes, no período compreendido entre 01 de julho de 2017 e 30 de junho de 2018.

Tabela 1 - Número de notícias sobre algumas personalidades publicadas na comunicação social entre julho de 2017 e junho de 2018

\begin{tabular}{|l|c|c|}
\hline & N. ${ }^{\circ}$ de notícias & Percentual \\
\hline Presidente da FPF & 4190 & $33 \%$ \\
\hline Presidente da Liga & 3294 & $26 \%$ \\
\hline DirCom do FC Porto & 3748 & $29 \%$ \\
\hline DirCom do SL Benfica & 218 & $2 \%$ \\
\hline DirCom do Sporting CP & 1386 & $11 \%$ \\
\hline Total & $\mathbf{1 2 8 3 6}$ & $\mathbf{1 0 0 \%}$ \\
\hline
\end{tabular}

Fonte: Elaboração própria (a partir de dados da Cision).

Como podemos verificar, entre os DirCom, é o do Porto quem ocupa mais notícias, quase 3800, seguindo o do Sporting, a rondar as 1400 notícias, e num patamar muito distante, com pouco mais de 200 notícias, o DirCom do Benfica. Já o presidente da FPF e o presidente da Liga totalizam, respetivamente, 4190 e 3294 notícias. Salientamos que a FPF é a entidade responsável pela seleção nacional, campeã europeia, o que é fato inédito no futebol português, e a Liga é a instituição organizadora da Liga NOS. Ao compararmos o número de notícias sobre os presidentes e os DirCom, verificamos que a diferença é mínima, chegando mesmo o DirCom do Porto a registrar mais notícias que o presidente da Liga. Estes dados são elucidativos quanto à centralidade midiática dos DirCom, mas também quanto ao posicionamento dos DirCom, sobretudo do registro mais low-profile do DirCom do Benfica, que analisaremos mais à frente.

A análise efetuada permite-nos constatar que estamos perante práticas comunicacionais do tipo unidirecional, enquadráveis nos dois primeiros modelos de Grunig \& Hunt (1984) e que evidenciam a alteração do ecossistema comunicacional dos clubes, reforçada com a utilização das suas próprias plataformas de comunicação. É importante sublinhar que esta utilização por parte dos clubes faz com que a intermediação jornalística, até aqui prática corrente nas relações com a mídia, deixe de ser necessária. Se mais não fosse, esta situação permitiria desde logo afirmar uma posição única, no caso a do clube, sem necessidade ou mesmo possibilidade (uma

\footnotetext{
${ }^{5}$ Encarnado por analogia à cor (vermelho) do equipamento do Benfica.
} 
vez que os clubes não o permitem) de qualquer contraditório. Este cenário não andará muito longe daquilo que se passa em regimes totalitários e no uso das práticas propagandísticas, tanto mais que os clubes de futebol, embora sufraguem seus dirigentes numa eleição colegial, são, no entanto, marcadamente presidencialistas.

Sublinhamos que os DirCom reportam diretamente aos presidentes dos clubes, pelo que seria também interessante analisar as práticas comunicacionais desses últimos. Fica uma reflexão para o tipo de totalitarismo clubístico a que assistimos e que só não impera no seu todo porque Portugal é um país democrático e com uma imprensa livre. Mas também há que sublinhar que isso não invalida que a imprensa livre esteja condicionada no acesso aos conteúdos dos clubes e que tenha de fazer acordos, numa lógica de sobrevivência e de negócio (Moragas, 2012).

Com a digitalização da comunicação, a blogosfera e as redes sociais são utilizadas de forma mais intensa e "os clubes contribuem mutuamente na orientação dos fluxos de informação e simultaneamente no processo de influência” (Gouveia \& Cardoso, 2019, p. 221). Para além das plataformas oficiais dos clubes, as diversas redes de torcedores constituem antenas poderosíssimas (redes sociais e blogs) com milhares de seguidores, mais ou menos alinhadas com os diferentes clubes e suas administrações (Kumar, 2009). Anselmo Crespo (Crespo, 2018) considera que o conflito vivido, veio "alimentar um monstro: a paixão dos torcedores que, umas vezes movidos pela emoção e outras pela irracionalidade, consomem tudo sem nada ruminar, para depois regurgitarem nos cafés, à porta dos estádios e nas redes sociais". Esta é uma situação que os DirCom conhecem e que por certo consideram nas suas estratégias.

Como afirma Américo Ramalho (Ramalho, 1982), é através de mensagens comunicativas (informação) atuando sobre a mente humana que o poder se desenvolve e é isso que os clubes, através dos seus DirCom, tentam fazer. Estes chamaram a si as luzes dos holofotes, assumindo um novo posicionamento comunicacional, uma tentativa de atuar e influenciar os seus públicos que, sendo sobretudo estratégica, é igualmente política (Shi \& Wilson, 2017).

O conflito foi-se agudizando, aparentemente incontrolável e perigoso, sobretudo por se tratar dos maiores clubes portugueses envolvidos, com milhões de torcedores, numa guerra em que os DirCom foram parte ativa. Tanto assim foi que o presidente da FPF, Fernando Gomes, em ato inédito, publicou simultaneamente em diversos diários um artigo de opinião com forte impacto midiático, onde alertava para os riscos que se corria e para a necessidade de paz (Gomes, 2017, p. 20). ${ }^{6}$ Três meses após a publicação desse artigo, o presidente da Liga alertou para a responsabilidade acrescida que cabe aos "três grandes", por serem aqueles que "mobilizam as massas" (Proença, 2018, p. 20). Colocou ainda no centro das preocupações a nova realidade comunicacional e o ambiente de litígio, contrário aos interesses da indústria do futebol, responsabilizando os DirCom por isso: "os diretores de comunicação não podem ser contratados pelos clubes para serem corrosivos". Esta crítica direta ao trabalho do DirCom, por aquele que é o responsável máximo pela organização da Liga NOS, e as outras situações que analisamos levam-nos a questionar: será que estas alterações melhoraram a eficácia comunicacional e, sobretudo, contribuem para os fins organizacionais dos clubes?

Esse estudo de caráter exploratório centra-se no emissor e não em eventuais efeitos sobre os receptores, pelo que não poderá responder a essa questão. No entanto, podemos partilhar uma reflexão de Paquete de Oliveira (Oliveira J. M., 2017) a propósito dos opinion makers portugueses, em que diz que "por vezes parece que o barulho ensurdecedor entre uns e outros é tanto, que quem está a ganhar com isso não são os que falam ou escrevem, mas aqueles que, encobertos neste ruído, fazem no seu silêncio desenvolver outras estratégias". Se quanto à

\footnotetext{
${ }^{6}$ Esse artigo foi publicado em 22 de setembro de 2017, em simultâneo nos três diários desportivos (A Bola, Record e O Jogo) e num diário de referência nacional ( $O$ Público).
} 
eficácia comunicacional não conseguimos aferir os resultados, já quanto às estratégias desenvolvidas poderemos levantar a hipótese de estas prosseguirem uma tentativa de agregação interna (sócios e torcedores), em torno de um inimigo externo (adversário). Essa é acompanhada por mecanismos de pressão sobre atores do fenómeno futebolístico, no sentido de retirarem dividendos para o clube e para os seus dirigentes. Mas não nos parece despropositado que esta situação também possa passar por vezes pela prática de um processo de desculpabilização, no que diz respeito ao insucesso esportivo.

Face ao que vimos relatando, poderíamos ser levados a pensar que os DirCom do Porto, Francisco J. Marques (FJM), do Benfica, Luís Bernardo (LB), e do Sporting, Nuno Saraiva (NS), nada teriam em comum; no entanto, apesar das conhecidas divergências clubísticas, os dados nos revelam o contrário.

A variável demográfica é apresentada na tabela 2. Os DirCom do Porto e do Benfica nasceram no mesmo ano e são cinco anos mais velhos do que o DirCom do Sporting, tendo todos eles em torno dos 50 anos. Essa é também uma função marcadamente masculina, com os DirCom nascidos na zona de influência da sede dos seus clubes. Este dado parece evidenciar a opção por profissionais maduros, em linha com o que passa em diferentes setores de atividade ao nível europeu (Zerfass et al., 2018).

Tabela 2 - DirCom: demografia

\begin{tabular}{|l|l|l|l|}
\hline Dados demográficos & \multicolumn{1}{|c|}{ FJM (Porto) } & \multicolumn{1}{c|}{ LB (Benfica) } & \multicolumn{1}{c|}{ NS (Sporting) } \\
\hline Nome & Francisco J. Marques & Luís Bernardo & Nuno Saraiva \\
\hline Gênero & Masculino & Masculino & Masculino \\
\hline Data de nascimento & $01 / 05 / 1966$ & $04 / 05 / 1966$ & $22 / 06 / 1971$ \\
\hline $\begin{array}{l}\text { Local de } \\
\text { nascimento/residência }\end{array}$ & Miranda do Corvo/Porto & Lisboa & Lisboa \\
\hline
\end{tabular}

Fonte: Elaboração própria (a partir de Henriques, 2007; Marques \& Faria, 2017; Palma, 2017; Ralha 2017).

A variável educacional é apresentada na tabela 3. Em termos de formação acadêmica, todos os DirCom têm frequência do ensino superior, mas em áreas muito díspares. FJM e LB graduaram-se em Engenharia e Direito, enquanto NS não terminou a graduação em Ciências da Comunicação. A área de conhecimento per se não se revela diferenciadora nos perfis estudados e esses também não divergem do que se passa com os DirCom europeus de outras indústrias (Zerfass et al. 2018).

Tabela 3 - DirCom: educação

\begin{tabular}{|l|l|l|l|}
\hline \multicolumn{1}{|c|}{ Educação } & \multicolumn{1}{|c|}{ FJM (Porto) } & \multicolumn{1}{c|}{ LB (Benfica) } & \multicolumn{1}{c|}{ NS (Sporting) } \\
\hline Habilitações & Graduado & Graduado & Frequência de curso de graduação \\
\hline Curso & Engenharia & Direito & Ciências da Comunicação \\
\hline
\end{tabular}

Fonte: Elaboração própria (a partir de Henriques, 2007; Marques \& Faria, 2017; Palma, 2017; Ralha 2017).

A variável da carreira profissional é apresentada na tabela 4. Os DirCom dos três grandes iniciaram as suas carreiras profissionais praticamente em simultâneo e todos eles pelo jornalismo, FJM (Porto) e LB (Benfica) em 1990, NS (Sporting) um ano depois. Com quase três décadas de experiência profissional, FJM e NS mantiveram-se fiéis ao jornalismo, não 
conhecendo outras atividades profissionais até ingressarem nos respectivos clubes. Ambos tiveram experiência em diferentes meios, na imprensa (jornais e revistas), agência de notícias, no caso de FJM, e rádio, no caso de NS.

No que respeita à área jornalística, FJM trabalhou no esporte, enquanto NS e LB na política. São profissionais sólidos (Tench et al., 2017), evidenciando-se a opção clara pela senioridade profissional, o domínio das mídias via jornalismo, a experiência de gestão pelos lugares exercidos e a componente política, a qual aparece de forma vincada.

Tabela 4 - DirCom: carreira profissional

\begin{tabular}{|l|l|l|l|}
\hline Carreira Profissional & \multicolumn{1}{|c|}{ FJM (Porto) } & \multicolumn{1}{|c|}{ LB (Benfica) } & \multicolumn{1}{|c|}{ NS (Sporting) } \\
\hline Início & 1990 & 1990 & 1991 \\
\hline Função anterior & Editor de esporte & Partner & Direção \\
\hline Entidade anterior & Agência Lusa & WL Partners & Diário de Noticias \\
\hline Área profissional & Jornalismo & Consultoria & Jornalismo \\
\hline Percurso profissional & $\begin{array}{l}\text { Público, Jornal } \\
\text { de Noticias, } \\
\text { Agência Lusa }\end{array}$ & $\begin{array}{l}\text { Jornalista na TVI (1990); Assessor: do } \\
\text { ministro da Cultura (1997); do } \\
\text { primeiro-ministro (1999); do Grupo } \\
\text { SAG (2002); do ministro da Presidência } \\
\text { (2005); do primeiro-ministro (2006/11); } \\
\text { do Partido Socialista (2013/15); WL } \\
\text { Partners }\end{array}$ & $\begin{array}{l}\text { Sábado (2003) } \\
\text { (1991); TSF (1995); }\end{array}$ \\
\hline
\end{tabular}

Fonte: Elaboração própria (a partir de Henriques, 2007; Marques \& Faria, 2017; Palma, 2017; Ralha 2017).

LB (Benfica) é quem apresenta um percurso mais diversificado e o mais político. Iniciou a carreira na televisão, onde se manteve até deixar o jornalismo em 1997 para assumir a assessoria de comunicação do ministro da Cultura Manuel Maria Carrilho (com quem trabalha atualmente na WL Partners). Dois anos mais tarde foi assessorar o primeiro-ministro António Guterres (atual Secretário-Geral da Organização das Nações Unidas) e depois o primeiroministro José Sócrates. Nesse governo, teve uma breve passagem inicial pela assessoria do ministro da Presidência, Pedro Marques (com quem trabalhou na TVI). Na mudança do ciclo político, quando o Partido Socialista (PS) deixou de governar, entre os governos de Guterres e Sócrates, teve uma experiência no universo empresarial, assessorando o Grupo SAG (20022005). No final do governo Sócrates, com o regresso do Partido Socialista à oposição, trabalhou na comunicação do PS, durante a liderança de António José Seguro. Entretanto, já tinha fundado a empresa WL Partners, na qual irá trabalhar com o Sporting na época de 2015/16.

FJM (Porto) e NS (Sporting) mudaram de atividade e deixaram o jornalismo, para trabalharem nos seus clubes, primeiro FJM, em 2011, e NS cinco anos mais tarde. É coincidentemente em 2016 que os três se cruzam pela primeira vez no mundo do futebol, ao assumirem as direções de Comunicação do Porto, do Benfica e do Sporting. FJM, embora no Porto desde 2011, apenas em 2016 assume a Comunicação. Por seu lado, LB, que na época anterior, de 2015/16, era o responsável pela comunicação do Sporting (via WL Partners), é substituído por NS e assume a comunicação do Benfica.

Como é possível verificar, estamos perante profissionais com uma forte rede de contatos, sabendo-se da importância destes nas relações desenvolvidas nas organizações (Tench et al., 2017, p. xxxi). Nos clubes, era prática corrente ter na função de DirCom profissionais provenientes do jornalismo esportivo e, no Porto, ainda assim é. Nos últimos cinco anos, a função de DirCom no Benfica e no Sporting tem sido ocupada por profissionais provenientes 
do mundo empresarial ou político. Será esta uma tendência? Será uma consequência do novo paradigma de comunicação dos clubes? São questões cuja evolução queremos acompanhar em trabalhos futuros.

A variável da integração na estrutura organizacional é apresentada na tabela 5. Todas as organizações são Sociedades Anónimas Desportivas (SAD) e cotadas em Bolsa.

Tabela 5 - DirCom: integração na estrutura organizacional

\begin{tabular}{|c|c|c|c|}
\hline $\begin{array}{c}\text { Estrutura } \\
\text { organizacional }\end{array}$ & FJM (Porto) & LB (Benfica) & NS (Sporting) \\
\hline Tipo de organização & $\mathrm{SAD}$ & $\mathrm{SAD}$ & $\mathrm{SAD}$ \\
\hline Cotada em Bolsa & Euronext Lisbon & Euronext Lisbon & Euronext Lisbon \\
\hline Designação da função & $\begin{array}{l}\text { Diretor de Comunicação e } \\
\text { Informação }\end{array}$ & Diretor de Comunicação & Diretor de Comunicação \\
\hline Posição hierárquica & N-1 & N-1 & N-1 \\
\hline Entrada no clube & 2011 & 2016 & 2016 \\
\hline Início da função & 2016 & 2016 & 2016 \\
\hline Experiência em clubes & Não & $\operatorname{Sim}$ & Não \\
\hline Sócio do clube & $\operatorname{Sim}$ & Sim & $\operatorname{Sim}$ \\
\hline
\end{tabular}

Fonte: Elaboração própria (a partir de Henriques, 2007; Marques \& Faria, 2017; Palma, 2017; Ralha 2017).

Entrando em diferentes anos, é, no entanto, em 2016 que todos os DirCom desta pesquisa assumem a responsabilidade pela Comunicação, sendo que o do Sporting não detinha ainda qualquer experiência profissional no futebol. O DirCom do Benfica contava já com a experiência da época anterior, no Sporting. No Porto, o DirCom já estava no clube há cinco anos. Tanto o DirCom do Benfica (em 2015), como o do Sporting (em 2016), quando iniciaram funções na comunicação do futebol, tiveram entrada direta neste setor profissional, no qual nunca tinham antes trabalhado. A função de DirCom reporta hierarquicamente ao presidente/à administração. São todos eles "homens do presidente" (Messika, 1994), homens do poder que, enquanto elementos de staff, têm a possibilidade de aconselhar/influenciar a tomada de decisão. $\mathrm{O}$ fato de serem todos sócios dos respetivos clubes reforça o vínculo à organização, o qual, para além de profissional, é também afetivo.

A variável da utilização de plataformas de comunicação é apresentada na tabela 6 .

Tabela 6 - DirCom: utilização de plataformas de comunicação

\begin{tabular}{|l|c|c|c|}
\hline \multicolumn{1}{|c|}{ Plataformas } & FJM (Porto) & LB (Benfica) & NS (Sporting) \\
\hline $\begin{array}{l}\text { Programa de } \\
\begin{array}{l}\text { TV em canal } \\
\text { do clube }\end{array}\end{array}$ & Universo Porto (Porto Canal) & Chama Imensa (BTV) & Verde no Branco (Sporting TV) \\
\hline $\begin{array}{l}\text { Rede social } \\
\text { privilegiada }\end{array}$ & Twitter & n.a. & Facebook \\
\hline
\end{tabular}

Fonte: Elaboração própria (a partir de Henriques, 2007; Marques \& Faria, 2017; Palma, 2017; Ralha 2017).

Os DirCom emergiram no espaço público não apenas como gestores da comunicação, mas também como seus protagonistas, tanto nos meios tradicionais, como nos digitais. Nas 
redes sociais, FJM (Porto) e NS (Sporting) mostraram-se muitos ativos nas suas redes de eleição, FJM no Twitter e NS no Facebook. LB (Benfica), por seu lado, não personalizou nenhuma rede social, utilizando apenas as do Benfica.

Dos três DirCom, LB foi quem assumiu um posicionamento mais low-profile, que o próprio assume como intencional, pois, como afirma, é "muito crítico do excesso de visibilidade dos diretores de comunicação. Quem deve ser a imagem pública de um clube é o presidente, os seus órgãos sociais, os jogadores e os técnicos. O diretor de comunicação de um clube deve ser reservado e só aparecer em circunstâncias muito específicas" (Record, 2017). Apesar de conhecermos o seu posicionamento, não deixamos de ficar surpreendidos nas pesquisas que realizamos, via Google, pela escassa informação disponível a seu respeito face ao que esperávamos, tratando-se de alguém que tem um trajeto profissional de destaque, com lugares midiáticos que ocupou e ocupa. O modelo de comunicação seguido pelo Benfica com LB contrasta com a prática seguida pelo seu antecessor. O ex-DirCom do Benfica, João Gabriel, com um perfil igualmente político, foi jornalista e assessor do ex-presidente da República, Jorge Sampaio, era o rosto do Benfica e publicamente conhecido pela constante guerrilha midiática que alimentava a partir da sua conta no Twitter.

O posicionamento comunicacional dos DirCom do Porto e do Sporting foi oposto ao de LB (Benfica) e mais próximo daquilo que seguiu o antecessor desse último. FJM (Porto) e NS (Sporting) foram sempre os rostos visíveis e permanentes do combate, assumindo publicamente a defesa das posições dos seus clubes, tanto na imprensa como nas plataformas de comunicação do clube. Para além das redes sociais, usaram os canais de TV dos clubes e participaram em programas como comentaristas residentes. LB (Benfica), embora sem ter presença fixa na tabela de programas da BTV, passou gradualmente a ser um rosto com aparições regulares no canal do clube. As intervenções dos DirCom, tanto nas redes sociais como nos canais do clube, ecoavam nos demais meios de comunicação social, amplificando as suas mensagens e audiências.

A variável das preferências políticas é apresentada na tabela 7. Do ponto de vista político e das preferências individualmente assumidas, apenas LB (Benfica) é formalmente militante partidário, no caso, do Partido Socialista (PS). Já NS (Sporting) foi militante da Juventude Comunista Portuguesa, abandonando por questões éticas quando ingressou no jornalismo, ao considerar que haveria incompatibilidade. Atualmente, afirma que já não é comunista, mas assume-se claramente como de esquerda. A FJM (Porto) não é conhecida militância partidária, mas já tornou público que vota no Bloco de Esquerda. Estamos perante DirCom de diferentes esquerdas, mas todos de esquerda.

Tabela 7 - DirCom: preferências políticas

\begin{tabular}{|c|c|c|c|}
\hline $\begin{array}{c}\text { Preferências } \\
\text { políticas }\end{array}$ & FJM (Porto) & LB (Benfica) & NS (Sporting) \\
\hline Partido político & $\begin{array}{c}\text { Simpatizante do Bloco } \\
\text { de Esquerda (BE) }\end{array}$ & $\begin{array}{c}\text { Militante do Partido } \\
\text { Socialista (PS) }\end{array}$ & $\begin{array}{c}\text { Foi militante da Juventude Comunista } \\
\text { Portuguesa (JCP), deixou ao ingressar } \\
\text { no jornalismo }\end{array}$ \\
\hline Quadrante político & Esquerda & Esquerda & Esquerda \\
\hline
\end{tabular}

Fonte: Elaboração própria (a partir de Henriques, 2007; Marques \& Faria, 2017; Palma, 2017; Ralha 2017). 
O perfil do DirCom pode assim ser sintetizado da seguinte forma:

- Gênero masculino, a rondar os 50 anos, nascido na zona de influência da sede do clube;

- Graduado ou com frequência universitária, com mais de 25 anos de experiência profissional, com passado no jornalismo e ocupando lugares de chefia;

- Trabalha em Sociedade Anônima Desportiva (SAD), cotada em Bolsa, reportando diretamente ao presidente / à administração;

- A relação com o clube não é apenas profissional, mas também afetiva, é sócio do clube "do coração";

- A política está-lhe no sangue e posiciona-se ideologicamente, numa dicotomia direitaesquerda, como assumidamente de esquerda.

A evolução da indústria do futebol, a sua maior mercantilização e midiatismo, trouxe aos clubes novas necessidades e exigências, sobretudo ao nível dos profissionais da comunicação, com outras serventias e competências, como pudemos verificar. No entanto, parece que a lógica de influência e poder desenvolvida individualmente terá esquecido aquilo que é o interesse comum, o seu próprio negócio (Proença, 2018), em que todos são parte integrante e interessada. Queremos com isto dizer que, se este é um fator vital de sucesso para seu todo, terá de sê-lo inevitavelmente para cada um individualmente e, sendo assim, não pode ser esquecido.

\section{Conclusões}

O perfil identificado dos DirCom, relativo aos dados demográficos, educação, status profissional e experiência profissional está em consonância com o perfil dos DirCom europeus para funções de similar responsabilidade em outros setores de atividade (Zerfass et al., 2018). Esse perfil vai ao encontro do que Tench et al. (2017) preconizam para comunicadores excelentes: profissionais sagazes, conectados e sólidos. Os DirCom dos "três grandes" são profissionais maduros com cerca de 25 anos de experiência profissional relevante. Exerceram lugares de chefia ao longo das suas carreiras profissionais, detêm formação superior, ou seja, "são bem instruídos, experientes e possuem competências explícitas necessárias para o desempenho em seus trabalhos" (Zerfass et al., 2018, p. xxxi), o que se exige a comunicadores de alto desempenho.

O DirCom, mais do que o responsável pela comunicação das organizações, é sobretudo o "homem do presidente" e a este está fortemente vinculado (Messika, 1994), como se veio a verificar no final da época desportiva de 2017/18, em que a saída do presidente do Sporting arrastou consigo também a do DirCom. Trata-se, portanto, de um homem do poder.

A maior centralidade do DirCom poderá ser explicada pelo facto de se tratar de profissionais reconhecidos, "conectados" e com uma poderosa rede de contatos, pois "as organizações não são nada além de conjuntos de relacionamentos entre pessoas dentro e fora das organizações" (Tench et al, 2017, p. xxxi), mas também porque querem ser vistos como poder, para assim o exercer, influenciar ou condicionar. Outro ponto que poderá justificar o seu protagonismo relaciona-se com a própria digitalização das mídias e a alteração dos modelos de comunicação dos clubes. Estes passaram a gerir de forma integrada os diversos registros da 
comunicação e ganharam a sua "independência" dos meios jornalísticos, ao entrarem numa lógica multiplataforma, tal como qualquer outro grupo de comunicação social.

O futebol é cada vez mais negócio, passando a comunicação a ter um papel cada vez mais preponderante no processo de decisão, nos jogos de poder e nas políticas traçadas, o que parece justificar a opção por um perfil de DirCom mais político e empresarial, em detrimento do tradicional jornalista esportivo que assumia a comunicação dos clubes. O negócio futebol pertence a Sociedades Anônimas Desportivas, empresas cotadas na bolsa de valores, só que essas são detidas majoritariamente pelos clubes, ou seja, são estes que indicam os administradores que gerem o negócio. No entanto, os torcedores continuam a ser alimentados pelos resultados esportivos e os "patrões" das SAD são os clubes, cujas direções são eleitas pelos votos dos torcedores, os quais são sócios. Eles exercem as suas opções com base na percepção que fazem daqueles que gerem os destinos do clube e a comunicação tem um papel determinante nesse processo.

As alterações verificadas na Champions League vieram agudizar a luta desenfreada pelos milhões que ela proporciona, uma vez que a presença nesta competição cava um fosso orçamental significativo relativamente aos demais. Em Portugal, apenas um time passou a ter acesso direto (anteriormente dois, mais um nas pré-eliminatórias), com o segundo a ter de disputar as pré-eliminatórias. Pensamos que fica claro: quando falamos dos "três grandes" e havendo apenas duas vagas, um desses clubes tem de ficar de fora.

Todas estas situações têm contribuído para a maior centralidade do DirCom, passando a atuar como "centroavante" do jogo midiático. No perfil que traçamos desses DirCom evidencia-se a opção por profissionais experientes que dominam a linguagem da mídia, o jogo político e o mundo dos negócios. Dominam as técnicas de comunicação e fazem uso das suas próprias plataformas de comunicação, privilegiando um modelo de comunicação unidirecional, sem contraditório, mais próximo de um registo propagandístico do que propriamente de relações públicas. É sabido, no entanto, que, de acordo com a literatura, a diferença é uma matéria complexa de definir e com fronteiras por vezes demasiado tênues (L'Etang, 2008).

A oportunidade de observar a atividade laboral diária de apenas um dos três DirCom, no caso o do Sporting, constitui naturalmente uma limitação do presente estudo. Caso tivesse sido possível, seria mais enriquecedor a observação também dos outros dois. Apesar disso, quanto à informação recolhida, se em alguns aspetos poderá sugerir apenas uma perspectiva, já as outras fontes do estudo permitem cruzar informações e ultrapassar essa limitação. A observação efetuada permite, contudo, que a partir daqui se desenvolvam futuramente outras pesquisas e mais ampliadas.

O aprofundar do conhecimento sobre o trabalho do DirCom e quem o exerce apresentase também como linha pertinente a explorar no futuro. Uma das abordagens interessantes para futuros trabalhos será aferir a eficácia deste novo posicionamento comunicacional dos DirCom, passando da lógica da emissão para nos centramos na recepção e perceber o impacto nos diversos stakeholders à luz dos fins organizacionais.

\section{Referências}

Abib, G., Hoppen, N., \& Junior, P. H. (2013). Observação participante em estudos de Aadministração da informação no Brasil. RAE: Revista de Administração de Empresas, 53 (6), 604-616.

Adler, P. A., \& Adler, P. (1987). Membership Roles in Field Research. Newbury Park: Sage

Publications.

Angrosino, M. (2009). Etnografia e Observação Participante. Porto Alegre: Artmed.

Balandier, G. (1999). O Poder em Cena. Coimbra: Minerva. 
Bardin, L. (1977). Análise de Conteúdo. Lisboa: Edições 70.

Berger, B. K., \& Reber, B. H. (2006). Gaining Influence in Public Relations: The Role of Resistance in Practice. London: Lawrence Erlbaum.

Bernays, E. (1923). Crystallizing Public Opinion. New York: Boni and Liveright.

Bernays, E. (1928). Propaganda. New York: Horace Liveright.

Cardoso, G., Xavier, D., \& Cardoso, T. (2007). Futebol, Identidade e Media na Sociedade em Rede. Observatorio $\left(O B S^{*}\right), 1,119-143$.

Castells, M. (2004). A Galáxia Internet. Lisboa: Fundação Calouste Gulbenkian.

Castells, M. (2009). Comunicación Y Poder. Madrid: Alianza Editorial.

Cheng, Y. (2018). Looking back, moving forward: a review an d reflection of the organization-public relationship (OPR) research. Public Relation Review, 44 (1), 120-130, https://doi.org/10.1016/j.pubrev.2017.10.003.

Cision (2018). Mais de meio milhão de notícias e 14 mil horas de futebol nos media portugueses. Obtido em 23 de janeiro de 2019, de Cision: http://news.cision.com/pt/cisionportugal/r/mais-de-meio-milhao-de-noticias-e-14-mil-horas-de-futebol-nos-mediaportugueses,c636797944130000000.

Coelho, J. N., \& Tesler, N. C. (2006). O paradoxo do jogo português: a ominipresença do futebol e a ausência de espectadores dos estádios. Análise Social, 41 (179), 519-551.

Cornelissen, J. (2011). Corporate Comunication (3rd ed.). London: Sage Publications.

Crespo, A. (2018). O futebol e o Estado que volta a falhar-nos. Obtido em 15 de janeiro de 2019, de Diário de Notícias: https://www.dn.pt/opiniao/opiniao-dn/anselmocrespo/interior/o-futebol-e-o-estadoque-volta-a-falhar-nos-9030554.html.

Cunha, T. C. (1999). Nota Introdutória. Em G. Balandier, O Poder em Cena. Coimbra: Minerva, pp. 11-13.

Cutlip, S. M., Center, A. H., \& Broom, G. M. (1999). Effective Public Relations. Prentice Hall International.

Daniel, C. (2016). Futebol a Sério. Lisboa: A Esfera dos Livros.

Daymon, C., \& Holloway, I. (2011). Qualitative Research Methods in Public Relations and Marketing Communications (2nd ed.). Oxon: Routledge.

DIRCOM. (2019). Estatutos aprobados Asamblea_General_Ordinaria. Obtido 14 de janeiro de 2019, de Asociación de Directivos de Communicación: http://www.dircom.org/images/Estatutos_aprobados_Asamblea_General_Ordinaria_17.06. 2017.pdf.

Eco, U. (1986). Il calcio secondo Eco: dal Grande Torino alla cultura della chiacchiera. (V. Sermonti, entrevistador, publicação original em L'Unità, 09 de junho de 1982). Obtido em 09 de junho de 2018, de La Repubblica:

http://carotenuto.blogautore.repubblica.it/2016/02/20/il-calcio-secondo-eco-dal-grandetorino-alla-cultura-della-chiacchiera/.

European Association of Communication Directors. (2008). European Communication Report. Brussels: Helios Media.

Fernandes, B. (2017). Nuno Saraiva mostra fatura de Red Pass com referência à "Claque NN", 23h32m. Obtido em 15 de janeiro de 2019, de Record: https://www.record.pt/futebol/detalhe/nuno-saraiva-mostra-fatura-de-red-pass-comreferencia-a-claque-nn.

Forte, H. (2017). Governo toma posição sobre tensão no futebol. A Bola, 23 de setembro, p. 40.

Freeman, R. E. (1984). Strategic Manegement: A Stakeholder Approach. Boston: Pitman Publishing. 
Gastaldo, É., \& Helal, R. (2013). Homo Ludens e o futebol-espetáculo. Revista Colombiana de Sociologia, 36 (1), 111-122.

Ginesta, X. (2009). Mediapro contra Sogecable: la guerra del futbol i la ineficaç regulació de l'Admininistració a Espanya (2006-2008). Observatorio $\left(O B S^{*}\right), 9,113-134$.

Giulianotti, R., \& Robertson, R. (2012). Mapping the global football field: a sociological model of transnational forces within the world game. British Journal of Socilogy, 63 (2), 216-240.

Gomes, F. (2017)). É tempo de responder aos sinais de alarme. A Bola, 22 de setembro, pp. 1 e 20.

Gonçalves, G. (2010). Introdução à Teoria das Relações Públicas. Porto: Porto Editora.

Gouveia, C., \& Cardoso, G. (2019). Twitando futebol: Benfica, FC Porto e Sporting na Liga NOS. PODIUM Sport, Leisure And Tourism Review, 8 (2), 211-229, https://doi.org/10.5585/podium.v8i2.13229.

Grunig, J. (1992). Excellence in Public Pelations and Communication Management. Hillsdale, NJ: Lawrence Erlbaum.

Grunig, J. E., \& Hunt, T. (1984). Managing Public Relations. Harcourt: Jocanovich.

Grunig, J. E., \& Jeong-Nam Kim. (2017). Public approaches to health and risk message design and processing. Em Oxford Encyclopedia of Health and Risk Message Design and Processing. Oxford University Press: Oxford Research Encyclopedias, pp. 1-37, https://10.1093/acrefore/9780190228613.013.322.

Grunig, J. E., \& Repper, F. C. (1992). Strategic management, publics and issues. Em J. E. Grunig (ed.), Excellence in Public Relation and Communication Management. Hillisdale: Lawrence Erlbaum Associates, pp. 117-157.

Grunig, J. E., Grunig, L. A., \& Dozier, D. M. (1996). Das situative model exzellenter public relations: Schlussfolgerungen aus einer internationalen studie (The contingency model of excellent public relations: Conclusions from an international study). Em G. Bentele, $\mathrm{H}$. Steinmann, \& A. Zerfass (Eds.), Dialogorientierte unternehmenskommunikation (Dialogueoriented approaches to communication). Berlin: Vistas, pp. 199-228 (série Public Relations/Offentlichkeitsarbeit und Organisationskommunikation, vol. 3).

Habermas, J. (1991). The Structural Transformation of Public Sphere: An Inquiry into a Category of Borgeois Society. Cambridge: The M IT Press.

Henriques, J. P. (2007). Luís Bernardo incapaz de compreender o jornalismo sem o ligar a interesses. Obtido em 23 de janeiro de 2019, de Diário de Notícias: https://www.dn.pt/arquivo/2007/interior/luis-bernardo-incapaz-de-compreender-ojornalismo-sem-o-ligar-a-interesses-655685.html.

Huang, Y.-H. C., \& Zhang, Y. (2015). Revisiting organization: public relationship research for the past decade. Em E.-J. Ki, J.-N. kim, \& J. A. Ledingham, Public Relations as Relationship Management. New York: Routledge, pp. 1-27.

Kapferer, J.-N. (2000). A Gestão de Marcas, Capital da Empresa. Mem Martins: Edições CETOP.

Kumar, R. (2009). Leituras de jogo: uma blogoesfera clubística. Em I. Brazão et al., Comunidades de Leitura: Cinco Estudos de Sociologia da Cultura, pp. 121-174.

L'Étang, J. (2006). Public relations and sport in promotional culture. Public Relations Review, 32, 386-394.

L'Etang, J. (2008). Public relations, persuasion and propaganda: truth, knowledge, spirituality and mystique. Em A. Zerfass, B. V. Ruller, \& K. Sriramesh (eds.), Public Relations Research. Wiesbaden: VS Verlag für Sozialwissenschaften, pp. 251-269. 
Ledingham, J. A. (2003). Explicating relationship management as a general theory of public relations, Journal of Public Relations Research, 15 (2), 181-198, doi:10.1207/S1532754XJPRR1502_4.

Lopes, F. (2011). As novas celebridades dos plateaux informativos: o primado da opinião de uma elite de jornalistas. Comunicação \& Cultura, 12, 61-81.

Lopes, F., Loureiro, L. M., \& Vieira, P. (2011). A confraria do comentário do futebol na TV: evolução dos programas. Observatorio (OBS*), 5 (4), 327-350.

Marivoet, S. (2009). Subculturas de adeptos de futebol e hostilidades violentas: o caso português no contexto europeu. Configurações: Revista de Sociologia, 5 (6), 279-299.

Marques, F. J., \& Faria, D. (2017). O Polvo Encarnado. Porto: Ideias de Ler.

Mcluhan, M. (1962). The Gutemberg Galaxy: The Making of Typographic Man. Toronto: The University of Toronto Press.

McLuhan, M. (1964). Os Meios de Comunicação como Extensões do Homem. São Paulo: Cultrix.

Messika, L. (1994). Dircoms et journalistes: une convergence du flou. Réseaux, 12 (64), 5374, https://doi.org/10.3406/reso.1994.2469.

Mintzberg, H., Ahlstrand, B., \& Lampel, J. (1998). Strategy Safari. New York: Free Press.

Moloney, K. (2006). Rethinking Public Relations, PR Propaganda and Democracy (2nd ed.). Oxon: Routledge.

Moragas, M. (2012). Deportes, medios de communicación e identidades en la sociedad global. Em J. Marques \& O. Morais, Esportes na Idade Mídia: Diversão, Informação e Educação. São Paulo: Edições Intercom, pp. 17-48.

Olabe, F. (2009). La gestión de la comunicación corporativa en los clubes profesionales en España. Observatório (OBS*), 10, 92-101.

Oliveira, J. M. (2017). Comunicação e Quotidiano. Lisboa: Tinta da China.

Palma, T. (2017). Nuno Saraiva e Francisco J. Marques eram jornalistas agora são notícia. Obtido em 15 de novembro de 2018, de Observador: https://observador.pt/especiais/nunosaraiva-e-francisco-j-marques-eram-jornalistas-agora-sao-noticia/.

Penn, R. (2016). Football talk: sociological reflections on the dialectics of language. Journal for Sport and Society, 13 (2), 154-166, doi:10.1080/16138171.2016.1183931.

Pinheiro, F. (2011). História da Imprensa Desportiva em Portugal. Porto: Afrontamento.

Proença, P. (2018). "Temos de baixar os decibéis" (A. Magalhães \& L. P. Sousa, entrevistadores). Record, 7 de fevereiro, 1 e 20-25.

Quintela, J. L. (2006). Comunicação Financeira: Transparência nos Sites das Empresas Cotadas. Lisboa: PressLivre.

Quintela, J. L. (2015). Comunicação financeira. Em S. Spínola \& N. Brandão (coords.), Relações Públicas e Comunicação Organizacional: Desafios da Globalização. Lisboa: Escolar Editora, pp. 277-310.

Quintela, J. L., Carvalho, S., Reis, J. R., \& Poupinha, L. (2007). The public relations brand: elements for the structuration of a concept. Em Euprera Congress 2005: New Challenges for Public Relations (10-13 Nov. Lisbon, Proceedings). Lisboa: Edições Colibri; IPL, pp. 71-80.

Ralha, L. (2017). Francisco J. Marques: o extremo esquerdo. Obtido em 23 de janeiro de 2019, de Correio da Manhã: https://www.cmjornal.pt/mais-cm/domingo/detalhe/franciscoj-marques-o-extremo-esquerdo.

Ramalho, A. (1982). A imagem institucional. Em Relations Publiques: Facteur de Communication Sociale. Lisboa: Instituto de Novas Profissões, pp. 56-68.

Record. (2018). Caso dos emails: a cronologia dos episódios que marcam a investigação. 6 de março. Obtido em 15 de janeiro de 2019, de Record: 
https://www.jornaldenegocios.pt/economia/detalhe/caso-dos-emails-a-cronologia-dosepisodios-que-marcam-a-investigacao.

Sá, J. d., \& Reto, L. (2002). Vox Popoli. Lisboa: Bertrand Editora.

Sanchez, F. O. (2009). La comunicación no convencional en los clubes de fútbol. Pensar la Publicidad, III (1), 121-137.

Santos, R. (1997). A Negociação entre Jornalistas e Fontes. Coimbra: Minerva.

Santos, R. M. (2019,). “Abomino cartilheiros” (B. V. Rainho, entrevistador). 19 de Janeiro. Jornal I, pp. 1 e 20-27.

Shi, X., \& Wilson, S. (2017). Influence. Em C. R. Scott (ed.), The International Encyclopedia of Organizational Communication, vol. II. Chichester: Wiley, pp. 1211-1223, doi:10.1002/9781118955567.wbieoc107.

Sobral, F. (2017). Futebol, O Estádio Global. Lisboa: Fundação Francisco Manuel dos Santos.

Sport Lisboa e Benfica. (2017). Agora. 20 de novembro. Obtido de SL Benfica: https://www.slbenfica.pt/pt-pt/agora/noticias/2017_2018/11/20/direto-benfica-chamaimensa-novo-apito-dourado-revelacoes-btv.

Tench, R., Verčič, D., Zerfass, A., Moreno, A., \& Verhoeven, P. (2017). Communication Excellence: How to Develop, Manage and Lead Exceptional Communications. London: Palgrave Macmillan, doi:10.1007/978-3-319-48860-8.

Wagg, S. (2007). Angels of us all? Football management, globalization and the politics of celebrity. Soccer \& Society, 8 (4), 440-458, https://doi.org/10.1080/14660970701440725.

Zerfass, A., Moreno, A., Tench, R., Verčič, D., \& Verhoeven, P. (2009). European Communication Monitor 2009: Trends in Communication Management and Public Relations. Results of a Survey in 34 Countries. Brussels: EACD; EUPRERA.

Zerfass, A., Tench, R., Verhoeven, P., D. Verčič, D., \& Moreno, A. (2018). European Communication Monitor 2018. Strategic Communication and the Challenges of Fake News: Trust, Leadership, Work Stress and Job Satisfaction. Results of a Survey in 48 Countries. Brussels; Berlin: EACD/EUPRERA; Quadriga Media Berlin. 